\title{
Elderly and Early Prostate Cancer
}

\author{
K. Stamatiou \\ Urology department Tzaneion General Hospital of Pireas
}

Greece

\section{Introduction}

Prostate cancer (PC) is the second most frequent malignant disease and the second-leading cause of cancer deaths among men in the United States (1). Both evidence and epidemiologic studies have shown that PC is rare in men younger than 50 years of age, but thereafter the risk of incident prostate cancer increases significantly with increasing age $\left.{ }^{2}\right)$. After the introduction and widespread use of the prostate-specific antigen (PSA) blood test, PC incidence has increased and it is expected that this disease is likely to become a more prominent and pressing problem in many countries as the percentage of elderly men increases (3). Actually declines in mortality at younger ages, medical advances, and better health care have resulted in longer life expectancy in both the developing and the developed world the last three decades. Statistics compiled by the United Nations showed that in 1999, $10 \%$ of the world population was 60 years and older $\left({ }^{4}\right)$. By 2050 , this percentage will rise to $22 \%$. In Hong Kong, where the proportion of elderly is even higher, it is estimated to rise to $40 \%$. Regarding male gender, the population over 65 years is expected to increase 4 -fold worldwide by $2050(5)$. Achievements of the 20th century have changed the world's demographic proportions without altering the epidemiology of PC. Indeed, PC still remains a disease of elderly men and thus, increased PC incidence could be partly attributed to the steadily growing ageing population (6).

While the majority of elderly PC patients in the past were diagnosed with local advanced or metastatic disease, a rising number of elderly men are now diagnosed with early stage PC. It is not known whether and if this is due to the effective utilization of health care resources or to the widespread use of PSA testing worldwide. Several studies however showed that after the introduction of PSA, additionally to the increase in the PC detection rate, an eventual shift towards earlier pathological stage was occurred also (3). The increased life expectancy enjoyed by the world population also means that the life span beyond age 60 is much longer than demographers have previously envisaged. Currently, a large proportion of the population remains active beyond the age of 70 and lives beyond the age of 80 . Since many of them are healthy, the number of elderly men who will be diagnosed with PC and may require treatment will further increase in the coming years $(7)$.

The aim of present study is to discuss the issue of screening for PC in elderly individuals as well as to review the current data on the treatment of early stage PC in elder males. A secondary aim is to examine whether or not advanced age impacts on PC risk. The impact of life expectancy on the choice of treatment in both patients and health care providers has been investigated also. 


\section{Methods}

We identified studies published from 1990 onwards by searching the MEDLINE database of the National Library of Medicine. Initial search terms were localized prostate cancer, early stage prostate cancer, combined with elderly patients, life expectancy, palliative, curative, quality of life, watchful waiting, radical prostatectomy, brachytherapy and external beam radiotherapy. References in the selected publications were checked for relevant publications not included in the Medline/Pubmed search.

\section{Results}

\subsection{How ageing can increase the risk of prostate cancer?}

A definitive cause of PC has not been identified and the specific mechanisms that lead to the development of the disease are still unknown. Although several risk factors have been proposed, the only risk factors that can be considered established are age, race and family history. Evidence suggests that an association between the above risk factors through a common pathogenic mechanism exists. On one hand, development and function of the prostate gland is endocrine controlled and androgen/estrogen synergism is necessary for the integrity of the normal human prostate. On the other hand androgen action is critical to the development, progression and cure of PC. Under those circumstances, it could be expected that ageing facilitate PC development through androgenic action. In fact, androgens undergo a significant age-dependent alteration: with ageing the production of testosterone by the testes is decreasing leading thus in a significant reduction of the endogenous testosterone levels. DHT activity decreases in the epithelium while in the stroma it remains constant over the whole age range. The age-dependent decrease of the DHT accumulation in epithelium and the concomitant increase of the estrogen accumulation in stroma lead to a tremendous increase of the estrogen/androgen ratio in the human prostate. Although, the specific pathway remains partially investigated, it is widely accepted that these alterations promote the initiation of benign prostatic hypertrophy, the most common disease of the ageing prostate. Similarly to benign prostatic hypertrophy, PC incidence increases with age: it seldom develops before the age of 40 and is chiefly a disease found in men over the age 65 years. Epidemiological evidence from autopsy studies show that while a very high proportion of elderly men has histological evidence of the disease, a much smaller proportion actually develop clinically apparent PC however, most of the impalpable cancers likely to progress and become clinically significant (advanced Gleason score, greater volume) are found in older individuals $\left(^{8}\right)$. However, age-related increase in the prevalence of prostate cancer found in autopsy is not similar worldwide. Variations in the reported incidence of $\mathrm{PC}$ between different racial groups suggest that some populations are either more susceptible to PC-promoting events or are exposed to different promoting agents $\left({ }^{9}\right)$. Take the above in consideration it could be speculated that ageing may promote clonal transformation events of pathogenetic importance for the initiation of PC. These clonal transformation events may be boosted by genetic predisposing factors. Although the exact pathways remain unknown, evidence suggests that they involving the androgen receptor (AR). The $A R$ is a structurally conserved member of the nuclear receptor superfamily and signalling via the AR is critical for carcinogenesis and progression of the disease. The AR's amino-terminal domain is required for transcriptional activation and contains a region of polyglutamine encoded by CAG trinucleotide repeats. As androgen 
influences prostate cancer growth, expansion of CAG repeats in the AR affect the risk of developing prostate cancer in a race and age depending matter $\left({ }^{10}\right)$.

Age-dependent clonal transformation events that affect the risk of developing prostate cancer may also occur to the Insulin-like Growth Factor-II (IGF-II) gene. The IGF-II gene is an auto- paracrine growth stimulator that is an important positive modulator of cancer development. IGF-II losses of imprinting, as well as increased lGF-II expression resulting from age-dependent changes in DNA methylation, have been recently associated with increased risk for PC development (11).

\subsection{The issue of screening for prostate cancer in elderly individuals}

A major consideration for cancer screening is to weigh up the possibility someone will have needless treatment against saving lives. PC can develop into a fatal, painful disease, but it can also develop so slowly that it will never cause problems during the man's lifetime. Actually, although none of the existing screening tools can accurately distinguish between lethal and indolent PC, the use of PSA has been shown to increase the PC detection rate with a shift to detection at earlier and therefore curable stages (12). This fact generated also concerns about over-diagnosis and over-treating and arguments both for and against the efficacy of screening. Under the light of this evidence it became clear why the issues of overdiagnosis and over-treating are of outmost importance when deciding to screen elderly individuals (13).

Data from US Cancer of the Prostate Strategic Urological Research Endeavor shows that most of the patients diagnosed with prostate cancer the last two decades in the US had low or intermediate disease at diagnosis (14). Moreover, between 20 and 30\% of PCs found in radical prostatectomy specimens of men with PSA-detected disease are non palpable, potentially indolent cancers (Gleason $<6$, tumor volume $<0,5 \mathrm{~cm} 3)(15,16)$. Since doubling time of high and intermediate differentiated prostatic carcinomas reaches 7 and 5 years respectively, a small tumor $(<0,5 \mathrm{~cm} 3)$ poses little threat for the life of older individuals (from the perspective that needs enough time to became life threatening). In confirmation to the above, Albertsen and colleagues demonstrated that men with prostate biopsy specimens showing Gleason score 2 to 4 disease faced a minimal risk of death from prostate cancer within 15 years from diagnosis (17). Given that life expectancy of American males at the age of 65 is 16 years $\left({ }^{18}\right)$ and the mean time to cancer-specific death of apparently clinically localized prostate cancer is 17 years $\left({ }^{19}\right)$, it became obvious why PC screening and treatment of PSA detected PCs in elderly patients is a controversial issue. Most doctors however argue against PSA testing for men who are in their 70s or older, because even if prostate cancer were detected, most men would be dead of something else before the cancer progressed $\left({ }^{20}\right)$. This is true only in part. As previously mentioned, today a large proportion of the population lives beyond age 70 and many are healthy. These men have several reasons -the belief in the benefit of early diagnosis, the need to have trust, and a desire for reliable screening resembling women- to undergo testing for prostate cancer. Yet, patient's anxiety increase the likelihood of getting the screening test, by acting powerfully on the screening decisions of physicians, whose clinical judgment would otherwise make them least, inclined to order the test ${ }^{(21)}$.

At the moment, PC screening is being performed unofficially in elderly patients visiting outpatient departments of general hospitals and consulting rooms. The exact magnitude of this opportunistic screening is not known however it is believed that reaches high numbers 
worldwide. Hoffman and associates and Walter and colleagues found a 56\% and 50\% PSA screening rate in their cohort of elderly men in 2003 and 2010, respectively $(22,23)$. Bowen and co-workers found that PC screening rates among men at the age of 80 and older are even higher than that of men in the age range of 50 to 64 years (64\% versus $56 \%)(24)$. Similarly, in a study by D'Ambrosio and colleagues, the highest yearly exposure to PSA screening and the highest frequency of repeat testing were observed in the age range of 70 to the 79 years (25). In contrast, Zeliadt and associates demonstrated that PSA testing among men older than 75 years has declined slightly following the recommendations by the US Preventive Services Task Force in 2008 and is still continuing to decline (15). Aus and colleagues found that restrictions in the use of PSA test in individuals over 75 years resulted in PC incidence falls after peaking at the age of $75(26)$. Interestingly, evidence suggests that PSA testing may be useful in diagnosis of aggressive early PC in a subset of elderly patients. A current study by Brassell and colleagues showed that as men age, parameters consistent with more aggressive disease become more prevalent (27) a fact that was confirmed by the findings of an autopsy study demonstrating that a proportion of elderly men with histologically apparent disease may develop lethal PC (21). Therefore it is not surprising that older individuals with clinically apparent PC usually die from PC. These data may have implications for future screening and treatment recommendations. Currently, age plays an important role in both screening decision and treatment choice and thus elderly patients are less likely to undergo PSA test and receive local therapy.

Data from US Cancer of the Prostate Strategic Urological Research Endeavor shows a significant reduction of risk of death from metastatic prostate cancer and a decrease in prostate carcinoma-specific mortality the last two decades in the US (14). As yet it is not possible to say what proportion of the fall in mortality is the result of improvements in treatment, changes in cancer registration coding, the attribution of death to $\mathrm{PC}$, and the effects of PSA testing. Accumulative evidence however suggests that early screening of PC in asymptomatic men reduce their risk of death from metastatic disease. Interestingly, the recently published results of the European Randomised Study for Screening of Prostate Cancer (ERSPC) reported a relative PC mortality reduction of at least $20 \%$ by PSA-based population screening $\left({ }^{28}\right)$ while Goel and Kopec reported an even higher reduction of risk of death from metastatic PC among men who were not screened regularly as part of a screening program $(29)$.

Given that PSA screening mainly diagnoses early PC, it may be justifiable for otherwise healthy elderly men to undergo PSA test. This is of outmost importance since older patients are more likely to have high-risk prostate cancer at diagnosis and lower overall survival. In fact, under-use of potentially curative local therapy among older men with high-risk disease may explain, at least in part, the observed differences in cancer-specific survival across age strata. $\left({ }^{30}\right)$. Taking in consideration these findings along with observations of Brassell and coworkers (27) it became obvious that evidence supports making decisions regarding screening on the basis of disease risk and life expectancy rather than chronologic age.

Currently, no standard recommendation for PC screening exists. Recently, the American Urological Association recommends PC screening to men aged 40 years or older. In contrast, screening is presently discouraged by the EC Advisory Committee on Cancer Prevention for its negative effects are evident and its benefits still uncertain (31). According to the U.S. Preventive Services Task Force, evidence is insufficient to recommend in favour of, or against routine PC screening (23). The abovementioned professional organizations and health agencies as well as most of medical experts agree that it is important that the benefits 
and risks of diagnostic procedures and treatment be taken into account when considering whether to undertake PC screening. On the other hand, treatment recommendations are now recognizing that older men with PC should be managed according to their individual health status, which is mainly driven by the severity of associated comorbid conditions, and not according to chronological age. According to the International Society of Geriatric Oncology Prostate Cancer Task Force, it is possible, based on a rapid and simple evaluation, to classify patients into four different groups: 1) "Healthy" patients (controlled comorbidity, fully independent in daily living activities, and no malnutrition) should receive the same treatment as younger patients; 2) "Vulnerable" patients (reversible impairment) should receive standard treatment after medical intervention; 3) "Frail" patients (irreversible impairment) should receive adapted treatment; 4) Patients who are "too sick" with "terminal illness" should receive only symptomatic palliative treatment.(30) The same rapid and simple evaluation may help physicians who perform PSA screening to decide who to screen.

\subsection{Treatment options and treatment decision making}

The main treatment options include radical prostatectomy (RP), radiotherapy (external beam radiotherapy and brachytherapy), watchful waiting (WW) and androgen deprivation therapy (ADT). Other include, cryotherapy (freezing the prostate), high-intensity focused ultrasound (HIFU), radiofrequency interstitial tumour ablation (RITA) and non-hormonal therapy (cytotoxic agents). Radical prostatectomy, brachytherapy and external beam radiotherapy are considered curative, while watchful waiting and hormone-therapy palliative. All treatments have risks of complications, although frequency and severity may vary. The primary goal of treatment is to target the men most likely to need intervention in order to prevent prostate cancer death and disability while minimizing intervention-related complications. However, whereas the standard oncologic evaluation works reasonably well in most other populations, in elderly PC patients, tends to overestimate possible harms associated with radical treatment and underestimate patients ability to withstand treatments side effects. In accordance to the above, various studies have demonstrated that potentially curative therapy (radical prostatectomy or radiotherapy) is applied less often in older PC patients $(32,33,34,35,36)$. Traditionally, PC is considering a slow progressive disease that needs enough time to become life threatening for an elder individual and this possibly explains the above observation. However, a multivariate analysis of the SEER database revealed significantly decreased odds of receiving cancer directed surgery in the elderly patient with lung, liver, breast, pancreas, esophageal, gastric cancers, sarcoma and rectal cancer while other studies have demonstrated under use of cancer directed radiation and chemotherapy $(37,38,39)$. These findings are posing justifiable concern about under-treatment of the elderly cancer patient and raise the provocative question if this is due to judicious, evidence based selection or discrimination based only on age $\left(^{40}\right)$. The reasons for the observed under use of cancer directed treatment in the elderly remain elusive. However, discrimination -if presentreflects the stereotypes that older people are physically frail, unfit for curative treatment, indisposed to accept treatment related complications, impatient and uninterested in prolonging survival. With regard to PC treatment decision making, increasing age is definitely a risk factor for receiving inadequate treatment $\left({ }^{41}\right)$. Harlan et al demonstrated that advantaged age is- still- considering as important as PSA, clinical stage and Gleason score while other demonstrated that age is the predominant factor influencing treatment 
decision making: Alibhai and colleagues generated an age-stratified random sample of 347 men from a cohort of patients with newly diagnosed prostate carcinoma in the Ontario Cancer Registry. Patients who were younger than 60 years were more likely to receive radical prostatectomy than radiation therapy or no therapy. Men between 60 and 69 years of age were more likely to receive radiation therapy than radical prostatectomy. Men between 70 and 79 years were most likely to receive no therapy, and nearly all men over 80 years received no therapy $\left({ }^{42}\right)$. Basically, although age plays a key role in treatment decision making, age itself is not predictive of outcome in an elderly cancer patient. In contrast, treatment outcome is strictly associated with clinical parameters such as the tumor stage, tumor grade or Gleason score and PSA level and therefore, treatment selection should be balanced between clinical stage and remaining life expectancy. It should be noticed however that the 10-year rule currently used to estimate life expectancy in elderly PC patients has demonstrated limited predictive validity and its use in clinical decision-making doesn't decrease the likelihood of receiving inappropriate treatment in elderly individuals (31).

Regarding localized PC, available treatment options include established therapies such as WW, RP, brachytherapy and external beam radiotherapy and non established therapies such as minimal invasive techniques and early hormone-therapy ( $\left.{ }^{43}\right) . \mathrm{RP}$ is considering the gold standard for the treatment of localized PC and in fact it is the most common treatment with approximately 60,000 operations performed annually in the US (44). However, only a small number of elderly patients with early stage PC are treated with RP $\left({ }^{45}\right)$. The reason why advanced age is an unfavorable predictor of the probability of surgical treatment is not known (46). Actually, the fact that elderly individuals have lower life expectancy as well as the belief that elderly patients with localized disease are considering more prone to die with PC than of it, partly explain why PR is the less popular treatment of early PC in elderly patients. Moreover, elderly patients are often being considering fragile enough to receive surgical treatment. Whether and if age increase surgical risk is a controversial issue and for this reason several investigators claim that it is co-morbidity that actually increases the surgical risk and not ageing itself $\left({ }^{47}\right)$. Although, co-morbid illness has demonstrated increasing importance as a prognostic factor, its role is poorly defined. It is generally accepted that co-morbidity limits the generalization of results to older and sicker patients however; the widespread integration of co-morbidity into clinical practice has yet to be realized.

Reported differences in PC specific survival across age strata may be associated with under use of potentially curative local therapy among older men. In fact, PC mortality increases with ageing, peaks at the age of 70-75 and no significant decrease occurs thereafter (table 1). According to the SEER database, younger men (under age 65) with localized prostate cancer had 25-year prostate cancer mortality rates of approximately 19\% for Gleason 6 disease, 37\% for Gleason 7 disease, and 50\% for Gleason 8-10 disease (48). Given that the survival advantage of surgery is most pronounced in men with higher stage disease, it became obvious that elderly PC patients with aggressive disease and life expectancy $>10$ years are likely to die from progressive prostate cancer $\left({ }^{49}\right)$. Worth mentioning, Bechis et al. studied men in the Cancer of the Prostate Strategic Urologic Research Endeavor (CaPSURE) database with complete risk, treatment, and follow-up information. They found that older patients are more likely to have high-risk prostate cancer at diagnosis and less likely to receive local therapy (30). In confirmation to the above, Dahm et al.showed that risk of death from PC for elderly PC patients treated with PR is significantly lower when compared with 


\begin{tabular}{|c|c|c|}
\hline AGE & DEATHS & \% RATE \\
\hline $15-19$ & 0 & 0 \\
\hline $20-24$ & 1 & 0,0 \\
\hline $25-29$ & 2 & 0,0 \\
\hline $30-34$ & 1 & 0,0 \\
\hline $35-39$ & 4 & 0,0 \\
\hline $40-44$ & 20 & 0,1 \\
\hline $45-49$ & 71 & 0,3 \\
\hline $50-54$ & 233 & 0,9 \\
\hline $55-59$ & 722 & 2,8 \\
\hline $60-64$ & 1738 & 6,9 \\
\hline $65-69$ & 3123 & 12,5 \\
\hline $70-74$ & 4636 & 18,5 \\
\hline $75-79$ & 5337 & 21,4 \\
\hline $80-84$ & 4536 & 18,2 \\
\hline$>85$ & 4625 & 18,1 \\
\hline
\end{tabular}

Table 1. Age and PC specific mortality (US Public service 1989).

that of elderly PC patients treated with watchful waiting $\left({ }^{50}\right)$. Results from other studies showed that surgical therapy can achieve excellent oncologic results in selected elderly patients but they didn't found significant differences in overall survival $(51,52)$. According to the results of the Scandinavian Prostate Cancer Group (SPCG) study, radical prostatectomy is associated with less deaths from prostate cancer (10 vs.15\%), less deaths from any other cause ( 24 vs. $30 \%)$ and less metastases (14 vs. $23 \%)$ in a median follow-up of 8.2 years. However, benefit in cancer specific survival is limited to patients younger than 65 years.

On the other hand there are several facts supporting WW (deferring intervention until the advent of symptoms) as an ideal treatment of early PC in elderly patients: Epidemiological evidence from autopsy studies show that while a very high proportion of elderly men has histological evidence of the disease, a much smaller proportion actually develop clinically apparent PC (53). Several authors demonstrated that elderly patients with localized PC have a favorable outlook following WW $(54,55)$ and other showed that WW results in similar overall survival when compared with RP (56). In a pooled analysis of 828 case records from six nonrandomized studies, of men treated conservatively for clinically localized prostate cancer, Chodak et al, found an impressive $87 \%$ five years disease-specific survival rate $\left({ }^{57}\right)$, however other found that disease specific survival is better in patients who had undergone surgery and some authors argue that WW simply postpone the final treatment $(58,59,60,61)$.

Notably, there are no randomized clinical trials comparing surgery with radiation therapy in elderly PC patients, however an observational study, by Albertsen and colleagues showed that surgery is superior to radiation in localized prostate cancer in terms of prolonging overall and disease-specific survival (62).

The truth is that the preferred management of clinically localized prostate cancer is not known, due in large part to the paucity of randomized controlled trials comparing the effectiveness and harms across primary treatment options. It seems that age itself is the main determinant of treatment selection: according to the Swedish Cancer Register in men with localized tumors expectant treatment was much more commonly used in those aged $>$ or $=75$ years than in those aged $<75$ years $\left({ }^{63}\right)$. It is also clear that $\mathrm{WW}$ is an adequate 
approach for the treatment of early stage PC in patients suffering of live threatening diseases, unfit for radical treatment, however, it remains unclear whether and if treatment can be delayed until absolutely necessary with no detriment to curability in otherwise healthy elderly PC patients. Interestingly, Wong et al found no survival advantage associated with expectant treatment for localized PC in elderly men aged 65 to 80 years (64). Certainly observational data cannot completely adjust for potential selection bias and confounding, however these results clearly shows that specific factors other than tumor stage may contribute to WW failure. Given that PC exhibits a wide range of biologic behaviour, it could be assumed that disease specific survival outcomes in patients with localised PC following WW are associated with Gleason score or baseline PSA level: In the study of Johansson, only the $6 \%$ of patients with well differentiated PC, died of PC while mortality rates for intermediate and poorly differentiated cancers were $17 \%$ and $56 \%$ respectively (54). Soloway and associates reported an $85 \%$ treatment-free rate at 5 years on a small cohort of patients diagnosed with 'low-risk' prostate cancer managed by WW (65). Sandblom et al found also a great influence on survival and suggest the grade of malignancy to be taken into account when deciding on therapy (55).

The major risk of watchful waiting is that without treatment, prostate cancer can grow and spread outside the prostate capsule. In fact, even small, slow-growing tumors may become rapidly growing tumors and sometimes prostate cancer that appears to be small and slow growing may be larger and more aggressive than originally thought. Identification of patients who have a low probability of disease progression could be based on strict clinical and pathologic criteria such as Gleason score of 6 or less, a PSA level of $10 \mathrm{ng} / \mathrm{ml}$ or less, and stage T1c-T2a disease (66). Again, although patients with these characteristics have a much more favourable natural history and progression rate than those who have a higher Gleason grade or PSA level, in a substantial proportion of men tumours will still progress to advanced, incurable prostate cancer and death $\left({ }^{67}\right)$.

These data suggest that it is of outmost importance to distinguish between patients who are at higher risk and need active therapy and patients who are at low risk for disease progression and support making decisions regarding treatment on the basis of disease risk and life expectancy rather than on chronologic age $(68,69)$.

It therefore became clear that a comprehensive health status assessment is the key in distinguishing between frail and healthy elderly patients and in developing appropriate management approaches for these individuals. The geriatric assessment differs from a standard medical evaluation as it focuses on elderly individuals with complex problems and emphasizes functional status, co-morbidity and quality of life. Most importantly, comprehensive geriatric assessment frequently takes advantage of an interdisciplinary team of providers (urologists, radiation oncologists, medical oncologists and geriatricians).

Recently, the SIOG has developed a proposal of recommendations in this setting based on a systematic bibliographical search focused on screening, diagnostic procedures and treatment options for localised, locally advanced and metastatic prostate cancer in senior adults. Specific aspects of the geriatric approach were emphasised, including evaluation of health status (nutritional, cognitive, thymic, physical and psycho-social) and screening for vulnerability and frailty $\left({ }^{70}\right)$. According to the above elderly PC patients are classified in 4 groups. In Group 1 (no abnormality), patients are 'fit' and should receive the same treatment as younger patients; patients in Group 2 (one impairment in IADL or one uncontrolled comorbidity or at risk of malnutrition) are 'vulnerable' and should receive standard treatment after medical intervention; patients in Group 3 (one impairment in ADL or more 
than one uncontrolled comorbidity or severe malnutrition) are 'frail' and should receive adapted treatment; patients in Group 4 (dependent) should receive only symptomatic palliative treatment (32).

\section{Conclusions}

Actually, health status is more reliable prognostic factor for survival and treatment related outcomes in oncology than patient age and with this modern approach should be adapted in order to screening senior adults. Age, PSA level, histological grade, and comorbidities should be carefully balanced before making a treatment decision, in elderly men suffering from prostate cancer. Elderly men with limited life expectancy due to other significant lifelimiting medical conditions, such as chronic obstructive pulmonary disease and advanced coronary artery disease, are less likely to benefit from aggressive treatment and are candidate for a palliative approach Therefore, it is reasonable to withhold early detection through PSA screening in these patients thus avoiding the associated risks and impact on quality of life. In selected cases of healthy elderly patients and long life expectancy, PSA screening and curative treatment of undifferentiated prostate cancers could be considered as a rational choice.

\section{References}

[1] Jemal A, Thomas A, Murray T, Thun M. Cancer statistics, 2002. CA Cancer J Clin 2002;52:23-47.

[2] Levy I. Prostate cancer: the epidemiology perspective. Can J Oncol 1994;4 Suppl 1:4-7.

[3] United Nations Economic and Social Council.Concise report on world population (2000).

Report of the Secretary-General to the 33rd session of the Commission on Population and Development, 27-31 March 2000 available at: http://www.un.org/documents/ecosoc/cn9/2000/ecn92000-3.pdf.

[4] Siegel R, Ward E, et al. Cancer statistics, 2007. CA Cancer J Clin 2007;57:43-66.

[5] Jemal, A; Cheung FM. Ageing population and gender issues. In: Yeung YM, ed. New challenges for development and modernization: Hong Kong and the Asia-Pacific region in the new millennium. Hong Kong: Chinese University Press; 2002:20723.

[6] Crawford, ED. Epidemiology of prostate cancer. Urology 2003;62(6):3-12.

[7] AIRTUM Working Group. Italian cancer figures, Report 2010: Cancer prevalence in Italy. Patients living with cancer, long-term survivors and cured patients. Epidemiol Prev. 2010;34 (5-6 Suppl 2):1-188.

[8] Schutze U. Latent prostatic carcinoma -an autopsy study of men over 50 years of age. Zentralbl Allg Pathol. 1984;129(4):357-64.

[9] Breslow N, Chan CW, Dhom G, Drur-y RA, Franks LM, Gellei B et al. Latent carcinoma of prostate in seven areas. Int J Cancer 1977;20:680-688.

[10] Hardy DO, Scher HI, Bogenreider T, Sabbatini P, Zhang ZF, Nanus DM, Catterall JF. Androgen receptor CAG repeat lengths in prostate cancer: correlation with age of onset. J Clin Endocrinol Metab. 1996;81:4400-4405 
[11] Fu VX, Dobosy JR, Desotelle JA, Almassi N, Ewald JA, Srinivasan R, Berres M, Svaren J, Weindruch R, Jarrard DF.Aging and cancer-related loss of insulin-like growth factor 2 imprinting in the mouse and human prostate. Cancer Res. 2008;68(16):6797802.

[12] Smith DS, Catalona WJ, Herschman JD. Longitudinal screening for prostate cancer with prostate-specific antigen. JAMA. 1996;276:1309-1315.

[13] Woolf HS. Screening for prostate cancer with prostate- specific antigen: an examination of evidence. N Engl J Med 1995;333:1401-5.

[14] Cooperberg, MR; Lubeck, DP; Mehta, SS; Carroll, PR. Time trends in clinical risk stratification for prostate cancer: implications for outcomes (data from CaPSURE). J Urol. 2003;170(6 Pt 2):S21-S25.

[15] Epstein JI, Walsh PC, Carmichael M, Brendler CB. Pathologic and clinical findings to predict tumor extent of nonpalpable (stage T1c) prostate cancer. JAMA. 1994;271:368-374.

[16] Johansson, JE. Expectant management of early stage prostatic cancer: Swedish experience. J Urol. 1994;152:1753-1756.

[17] Albertsen PC, Hanley JA, Gleason DF, Barry MJ. Competing risk analysis of men aged 55 to 74 years at diagnosis managed conservatively for clinically localized prostate cancer. JAMA. 1998;280:975-980.

[18] Minino A, Smith BL. Deaths: preliminary data for 2000. Natl Vital Stat Rep. 2001;49:1-40 No author listed. US Public service, National Statistics Division. "Prostate cancer" National Statistics. Washton D.C.1983.

[19] Horan AH, McGehee M. Mean time to cancer-specific death of apparently clinically localized prostate cancer: policy implications for threshold ages in prostate-specific antigen screening and ablative therapy. BJU Int. 2000;85:1063-1066

[20] Scales C, Curtis L, Norris R, Schulman K, Albala D, Moul J. Prostate specific antigen testing in men older than 75 years in the United States. J Urol 2006;176(2):511-4.

[21] Haggerty J, Tudiver F, Brown JB, Herbert C, Ciampi A, Guibert R. Patients' anxiety and expectations. How they influence family physicians' decisions to order cancer screening tests. Can Fam Physician. 2005;51(12):1659.

[22] Hoffman RM, Barry MJ, Stanford JL, Hamilton AS, Hunt WC, Collins MM. Health outcomes in older men with localized prostate cancer: results from the Prostate Cancer Outcomes Study. Am J Med. 2006;119(5):418-25.

[23] Walter LC, Bertenthal D, Lindquist K, Konety BR. PSA screening among elderly men with limited life expectancies. Nat Clin Pract Urol. 2007;4(10):532-3.

[24] Bowen DJ, Hannon PA, Harris JR, Martin DP. Prostate cancer screening and informed decision-making: provider and patient perspectives. Prostate Cancer Prostatic Dis. 2011[Epub ahead of print].

[25] D'Ambrosio GG, Campo S, Cancian M, Pecchioli S, Mazzaglia G. Opportunistic prostate-specific antigen screening in Italy: 6 years of monitoring from the Italian general practice database. Eur J Cancer Prev. 2010;19:413-6.

[26] Aus G, Robinson D, Rosell J, Sandblom G, Varenhorst E, for the South-East Region Prostate Cancer Group. Survival in prostate carcinoma-outcome from a prospective, population-based cohort of 8887 men with up to 15 years of follow-up: 
results from three counties in the population-based National Prostate Cancer Registry of Sweden. Cancer. 2005;103:943-951.

[27] Brassell SA, Rice KR, Parker PM, et al. Prostate cancer in men 70 years old or older, indolent or aggressive: clinicopathological analysis and outcomes. J Urol. 2011;185:132-7.

[28] Schröder FH, Hugosson J, Roobol MJ, Tammela TL, Ciatto S, Nelen V, Kwiatkowski M, Lujan M, Lilja H, Zappa M, Denis LJ, Recker F, Berenguer A, Määttänen L, Bangma CH, Aus G, Villers A, Rebillard X, van der Kwast T, Blijenberg BG, Moss $\mathrm{SM}$, de Koning HJ, Auvinen A; ERSPC Investigators. Screening and prostatecancer mortality in a randomized European study. $N$ Engl J Med. 2009;360(13):1320-8

[29] Kopec JA, Goel V, Bunting PS, Neuman J, Sayre EC, Warde P, Levers P, Fleshner N. Screening with prostate specific antigen and metastatic prostate cancer risk: a population based case-control study. J Urol. 2005;174(2):495-9

[30] Bechis SK, Carroll PR, Cooperberg MR. Impact of age at diagnosis on prostate cancer treatment and survival. J Clin Oncol. 2011;29:235-41.

[31] Advisory Committee on Cancer Prevention. Position paper. Recommendations on cancer screening in European Union. Eur J Cancer 2000;36:1473-8

[32] Bennett CL, Greenfield S, Aronow H, Ganz P, Vogelzang NJ, Elashoff RM. Patterns of care related to age of men with prostate cancer. Cancer 1991;67(10):2633-41.

[33] Harlan LC, Potosky A, Gilliland FD, Hoffman R, Albertsen PC, Hamilton AS, Eley JW, Stanford JL, Stephenson RA. Factors associated with initial therapy for clinically localized prostate cancer: prostate cancer outcomes study. J Natl Cancer Inst. 2001;93(24):1864-71.

[34] Samet, J; Hunt, WC; Key, C, et al. Choice of cancer therapy varies with age of patient. JAMA 1986;255:3385-3390.

[35] Lu-Yao, GL; McLerran, D; Wasson, J; Wennberg, JE. An assessment of radical prostatectomy. Time trends, geographic variation, and outcomes. The Prostate Patient Outcomes Research Team. JAMA. 1993;269:2633-2636.

[36] Sverson, RK; Montie, JE; Porter, AT; Demers, RY. Recent trends in incidence and treatment of prostate cancer among elderly men. J Natl Cancer Inst. 1995;87:532534.

[37] Schrag D, Cramer LD, Bach PB, Begg CB. Age and adjuvant chemotherapy use after surgery for stage III colon cancer. J Natl Cancer Inst 2001;93:850 -7.

[38] Mahoney T, Kuo YH, Topilow A, Davis JM. Stage III colon cancers: why adjuvant therapy is not offered to elderly patients. Arch Surg 2000;135:182-5.

[39] O'Connell JB, Maggard MA, Ko CY. Cancer-directed surgery for localized disease: decreased utilization in the elderly. Ann Surg Oncol 2004;962-969.

[40] Fuchshuber P. Age and Cancer Surgery: Judicious Selection or Discrimination? Ann Surg Oncol. 2004;11(11):951-952

[41] Krahn, MD; Bremner, KE; Asaria, J, et al. The ten-year rule revisited: accuracy of clinicians' estimates of life expectancy in patients with localized prostate cancer. Urology. 2002;60:258-263. 
[42] Alibhai, SMH; Krahn, MD; Cohen, MM, et al. Is there age bias in the treatment of localized prostate carcinoma? Cancer. 2004;100:72-81.

[43] Anandadas CN, Clarke NW, Davidson SE, O'Reilly PH, Logue JP, Gilmore L, Swindell R, Brough RJ, Wemyss-Holden GD, Lau MW, Javle PM, Ramani VA, Wylie JP, Collins GN, Brown S, Cowan RA; North West Uro-oncology Group. Early prostate cancer--which treatment do men prefer and why? BJU Int. 2011 Jun;107(11):1762-8. doi: 10.1111/j.1464-410X.2010.09833.x. Epub 2010 Nov 17

[44] Healthcare Cost and Utilization Project (U.S.). United States Agency for Healthcare Research and Quality. http://www.ahrq.gov/data/hcup/hcupnet.htm. Accessed December 2006.)

[45] Schwartz KL, Alibhai SM, Tomlinson G, Naglie G, Krahn MD. Continued undertreatment of older men with localized prostate cancer. Urology. 2003 Nov;62(5):860-5.

[46] Carter HB, Epstein JI, Partin AW. Influence of age and prostate-specific antigen on the chance of curable prostate cancer among men with non palpable disease. Urology. 1999;53(1):126-30.

[47] Roberts CB, Albertsen PC, Shao YH, Moore DF, Mehta AR, Stein MN, Lu-Yao GL. Patterns and correlates of prostate cancer treatment in older men. Am J Med. 2011 Mar;124(3):235-43

[48] Wong YN, Wan F, Mitra N, et al. Treatment of localized prostate cancer: a survival analysis using SEER-Medicare data. Program and abstracts of the American Urological Association 2006 Annual Meeting; May 20-25, 2006; Atlanta, Georgia. Abstract 658.

[49] Inman BA, Slezak JM, Kwon ED, et al. 25-year outcomes of radical prostatectomy for the treatment of all stages of non-metastatic prostate cancer. Program and abstracts of the American Urological Association 2006 Annual Meeting; May 20-25, 2006; Atlanta, Georgia. Abstract 646.

[50] Dahm P, Silverstein AD, Weizer AZ, Crisci A, Vieweg J, Paulson DF. When to diagnose and how to treat prostate cancer in the "not too fit" elderly. Crit Rev Oncol Hematol. 2003;48(2):123-31

[51] Wilt TJ, Brawer MK, Barry MJ, Jones KM, Kwon Y, Gingrich JR, Aronson WJ, Nsouli I, Iyer P, Cartagena R, Snider G, Roehrborn C, Fox S. The Prostate cancer Intervention Versus Observation Trial:VA/NCI/AHRQ Cooperative Studies Program \#407 (PIVOT): design and baseline results of a randomized controlled trial comparing radical prostatectomy to watchful waiting for men with clinically localized prostate cancer. Contemp Clin Trials. 2009;30(1):81-7.

[52] Thompson RH, Slezak JM, Webster WS, Lieber MM. Radical prostatectomy for octogenarians: how old is too old? Urology. 2006 Nov;68(5):1042-5. Epub 2006 Nov 7.

[53] Pienta K, Esper PS, Risk Factors for Prostate Cancer Ann Int Med 1993; 118(10):793-803

[54] Johansson JE, Holmberg L, Johansson S, Bergström R, Adami HO. Fifteen-year survival in prostate cancer. A prospective, population-based study in Sweden. JAMA. 1997;277(6):467-71. 
[55] Sandblom G, Dufmats M, Varenhorst E. Long-term survival in a Swedish populationbased cohort of men with prostate cancer. Urology 2000;56(3):442-7

[56] Iversen P, Madsen PO, Corle DK. Radical prostatectomy versus expectant treatment for early carcinoma of the prostate. Twenty-three year follow-up of a prospective randomized study. Scan J Urol Nephrol Suppl 1995;172:65-72.

[57] Chodak GW, Thisted RA, Gerber GS, Johansson JE, Adolfsson J, Jones GW, Chisholm GD, Moskovitz B, Livne PM, Warner J. Results of conservative management of clinically localized prostate cancer. N Engl J Med. 1994;330(4):242-8

[58] Bill-Axelson A, Holmberg L, Filen F, et al. Radical prostatectomy versus watchful waiting in localized prostate cancer: The Scandinavian Prostate Cancer Group-4 randomized trial. J Natl Cancer Inst 2008;100:1144-54.

[59] McLaren DB, Watchful waiting or watchful progression? Prostate specific antigen doubling times and clinical behavior in patients with early untreated prostate carcinoma. Cancer. 1998;82:342-348

[60] Stattin P, Holmberg E, Bratt O, Adolfsson J, Johansson JE, Hugosson J; National Prostate Cancer Register. Surveillance and deferred treatment for localized prostate cancer. Population based study in the National Prostate Cancer Register of Sweden. J Urol. 2008;180(6):2423-9

[61] Makarov MV, Partin AW. Conflicting insights into the role of watchful waiting in the management of adenocarcinoma of the prostate Rev Urol. 2006;8(4):232-234

[62] Albertsen PC, Hanley JA, Penson DF, Fine J. Ten year outcomes following treatment for clinically localized prostate cancer: a population based study. Program and abstracts of the American Urological Association 2006 Annual Meeting; May 20-25, 2006; Atlanta, Georgia. Abstract 652.

[63] Adolfsson J, Garmo H, Varenhorst E, Ahlgren G, Ahlstrand C, Andrén O, Bill-Axelson A, Bratt O, Damber JE, Hellström K, Hellström M, Holmberg E, Holmberg L, Hugosson J, Johansson JE, Petterson B, Törnblom M, Widmark A, Stattin P. Clinical characteristics and primary treatment of prostate cancer in Sweden between 1996 and 2005. Scand J Urol Nephrol. 2007;41(6):456-77.

[64] Wong YN, Mitra N, Hudes G, Localio R, Schwartz JS, Wan F, Montagnet C, Armstrong K. Survival associated with treatment vs observation of localized prostate cancer in elderly men. JAMA. 2006; 296(22):2683-93.

[65] Soloway MS, Soloway CT, Williams S, Ayyathurai R, Kava B, Manoharan M. Active surveillance; a reasonable management alternative for patients with prostate cancer: the Miami experience. BJU Int. 2008;101(2):165-9.

[66] Epstein JI, Chan DW, Sokoll LJ, Walsh PC, Cox JL, Rittenhouse H, Wolfert R, Carter HB. Nonpalpable stage T1c prostate cancer: prediction of insignificant disease using free/ total prostate specific antigen levels and needle biopsy findings. J Urol 1998;160: 2407-2411

[67] Thaxton CS, Loeb S, Roehl KA, Kan D, Catalona WJ. Treatment Outcomes of Radical Prostatectomy in Potential Candidates for 3 Published Active Surveillance Protocols. Urology. 2010;75(2):414-8. 
[68] Klotz L. Active surveillance with selective delayed intervention: using natural history to guide treatment in good risk prostate cancer. J Urol. 2004 Nov;172(5 Pt 2):S4850.

[69] Berglund A, Garmo H, Tishelman C, Holmberg L, Stattin P, Lambe M. Comorbidity, treatment and mortality: a population based cohort study of prostate cancer in PCBaSe Sweden. Urol. 2011;185(3):833-9

[70] Droz JP, Balducci L, Bolla M, Emberton M, Fitzpatrick JM, Joniau S, Kattan MW, Monfardini S, Moul JW, Naeim A, van Poppel H, Saad F, Sternberg CN. Background for the proposal of SIOG guidelines for the management of prostate cancer in senior adults. Crit Rev Oncol Hematol. 2010 Jan;73(1):68-91. 


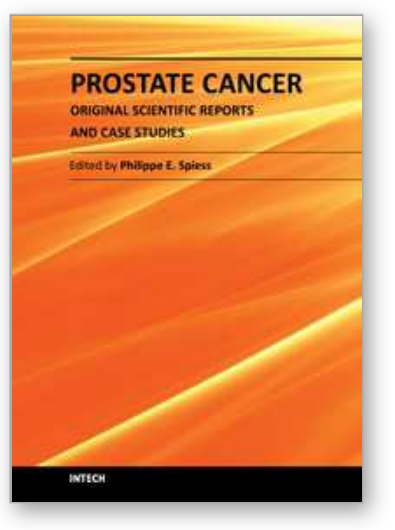

\author{
Prostate Cancer - Original Scientific Reports and Case Studies \\ Edited by Dr. Philippe E. Spiess
}

ISBN 978-953-307-342-2

Hard cover, 238 pages

Publisher InTech

Published online 21, November, 2011

Published in print edition November, 2011

This book encompasses three sections pertaining to the topics of cancer biology, diagnostic markers, and therapeutic novelties. It represents an essential resource for healthcare professionals and scientist dedicated to the field of prostate cancer research. This book is a celebration of the significant advances made within this field over the past decade, with the hopes that this is the stepping stone for the eradication of this potentially debilitating and/or fatal malignancy.

\title{
How to reference
}

In order to correctly reference this scholarly work, feel free to copy and paste the following:

K. Stamatiou (2011). Elderly and Early Prostate Cancer, Prostate Cancer - Original Scientific Reports and Case Studies, Dr. Philippe E. Spiess (Ed.), ISBN: 978-953-307-342-2, InTech, Available from: http://www.intechopen.com/books/prostate-cancer-original-scientific-reports-and-case-studies/elderly-andearly-prostate-cancer

\section{INTECH}

open science | open minds

\section{InTech Europe}

University Campus STeP Ri

Slavka Krautzeka 83/A

51000 Rijeka, Croatia

Phone: +385 (51) 770447

Fax: +385 (51) 686166

www.intechopen.com

\section{InTech China}

Unit 405, Office Block, Hotel Equatorial Shanghai

No.65, Yan An Road (West), Shanghai, 200040, China

中国上海市延安西路65号上海国际贵都大饭店办公楼 405 单元

Phone: +86-21-62489820

Fax: $+86-21-62489821$ 
(C) 2011 The Author(s). Licensee IntechOpen. This is an open access article distributed under the terms of the Creative Commons Attribution 3.0 License, which permits unrestricted use, distribution, and reproduction in any medium, provided the original work is properly cited. 